\title{
Geração de energia elétrica excedente no setor sucroalcooleiro: um estudo a partir das usinas paulistas
}

\author{
Zilmar José de Souza* \\ Paulo Furquim de Azevedo**
}

\begin{abstract}
Resumo: A geração de energia elétrica por parte do setor sucroalcooleiro encontra-se muito aquém de seu potencial. Este artigo tem por objetivo identificar os entraves para a ampliação da oferta de excedentes de energia elétrica pelo setor sucroalcooleiro, utilizando, para tanto, cinco estudos de caso com usinas paulistas. Os elevados custos associados à comercialização da energia elétrica - seja na venda de excedentes, seja na aquisição para consumo próprio - constituem a explicação mais plausível para a auto-suficiência na produção de energia elétrica pelo setor sucroalcooleiro, aliada à pequena geração de excedentes de energia para comercialização. Das cinco usinas estudas, as três que comercializam excedentes de energia o fazem como parte de uma estratégia de antecipação da necessidade futura de auto-suficiência. Havendo custos associados à venda de excedentes de energia elétrica, não há incentivos à utilização de tecnologias de maior eficiência energética. As políticas públicas voltadas à expansão dos excedentes de energia devem voltar-se para a redução dos custos associados à comercialização de excedentes de energia. Particularmente interessante é aumentar o volume de consumidores livres e amparar a comercialização entre estes e os co-geradores de energia.
\end{abstract}

Palavras-chave: Co-geração, setor sucroalcooleiro, energia elétrica

*Pós-doutorando em Economia pela FGV-EESP. zilmar.souza@energiasdobrasil.com.br

**Professor da FGV-EESP. pfa@fgvsp.br 
Abstract: The generation of electric energy by the sugarcane sector stands much below its potential. Using five case studies with São Paulo plants, this article aims to identify the obstacles to the expansion of the electric energy commercialization by the sugarcane sector. High costs associated to the commercialization of electric energy - in commercialization of excesses, and in the acquisition for proper consumption - are the most reasonable explanation for the self-sufficiency in the production of electric power by the sugarcane sector, an allied energy to the small generation of excesses of energy for commercialization. Out of the five plants studied, three plants that commercialize energy excesses make it as part of a strategy of anticipation of the future need of self-sufficiency. Having associated costs for sale of excesses of electric energy, they do not have incentives to the use of technologies of higher energy efficiency. The public policy directed to the expansion of energy excesses must turn toward the reduction of the costs associated to the commercialization thereof. Particularly interesting it would be to increase the volume of free consumers and to support the commercialization between these and the co-generators of energy.

Key words: Co-generation, sugarcane sector, electric energy.

J.E.L. Classification: L5, L8, L9.

\section{Introdução}

A geração de energia elétrica por parte do setor sucroalcooleiro encontra-se muito aquém de seu potencial. Mediante a adoção de tecnologias disponíveis de co-geração a partir do bagaço e da palha, apenas a produção de excedente de energia por parte das usinas paulistas seria capaz de suprir o déficit de toda a Região Sudeste, por ocasião do racionamento, durante a crise de 2001-2002 (SOUZA, 2004). Embora a participação do setor sucroalcooleiro seja modesta na oferta de excedentes de energia, as usinas de açúcar e álcool são praticamente auto-suficientes em energia, sendo $98 \%$ de sua demanda atendida pelo bagaço e os $2 \%$ restantes atendidos com óleo diesel, álcool, lenha, gasolina e a eletricidade comprada das distribuidoras. ${ }^{1}$

1 "A lenha é utilizada nas partidas das caldeiras, o diesel, o álcool e a gasolina são utilizados no transporte da matéria-prima e a energia elétrica comprada para atendimento de motores e iluminação" (CORRÊA NETO, 2001, p. 35). 
(CORRÊA NETO, 2001). A questão que se coloca é por que há auto-suficiência generalizada e uma produção de excedentes tão aquém do potencial?

Este artigo tem por objetivo identificar os entraves para a ampliação da oferta de excedentes de energia elétrica pelo setor sucroalcooleiro, utilizando, para tanto, cinco estudos de caso com usinas paulistas, desenvolvidos no primeiro semestre de 2003. O artigo estrutura-se em seis seções, incluindo esta introdução. A segunda seção destaca particularidades do mercado de energia elétrica e da co-geração a partir de bagaço, as quais estão na base das opções das usinas de açúcar e álcool ao atuarem nesse mercado. A terceira seção descreve o método de análise e procedimentos para a coleta de dados, que são utilizados na apresentação de cinco estudos de caso de usinas paulistas, os quais compõem a quarta seção. Uma análise comparada das usinas pesquisadas é o objeto da quinta seção, que indica os principais entraves para a geração de excedentes de energia pelo setor sucroalcooleiro. Finalmente, a sexta seção conclui com os principais resultados, limites da análise e sugestões de diretrizes de políticas públicas.

\section{Particularidades da co-geração de energia no setor sucroalcooleiro}

O setor sucroalcooleiro apresenta vários subprodutos, entre eles o bagaço da cana-de-açúcar. Apesar de considerado o maior dejeto da agroindústria nacional, seu aproveitamento industrial vai desde composto para ração animal, fertilizante, biogás, à matéria-prima para compensados e para indústria química em geral. No entanto, já no início do século passado, o bagaço era utilizado como combustível substituto à lenha. Anos depois, no início do século XXI, seu principal aproveitamento ocorre no processo de produção de energia (térmica e elétrica), conhecido como co-geração.

Segundo COELHO (1999), co-geração é a geração simultânea de energia térmica e mecânica, a partir de um mesmo combustível (gás natural, resíduos de madeira, casca de arroz, bagaço da cana, palha, ponteiros etc.). A energia mecânica pode ser utilizada na forma de trabalho ou transformada em eletricidade por meio de geradores; a energia térmica é utilizada como fonte de calor para um processo industrial ou no setor de comércio ou serviços. 
O potencial de geração de energia elétrica pelo setor sucroalcooleiro está relacionado diretamente à tecnologia empregada, devido aos custos unitários ( $\mathrm{R} \$ / \mathrm{kW}$ instalado) serem influenciados pelo efeito escala. A maior parte das usinas utiliza caldeiras de média pressão $\left(22\right.$ bar, $300^{\circ} \mathrm{C}$ ), apesar de disponíveis caldeiras de 40 a 100 bar, o que elevaria de forma significativa a eficiência energética. A troca de turbinas de simples para múltiplo estágio também traria efeitos positivos (COELHO, 1999, p. 54).

TOLMASQUIM, SZKLO \& SOARES (2002) afirmam que, considerando a colheita mecanizada e a utilização de palhas e pontas, em 2001, o potencial de co-geração de energia pelo setor sucroalcooleiro seria de 18.264 MW, podendo chegar a 21.309 MW até o ano de 2010, com o crescimento da área plantada.

Em outra estimação do potencial de co-geração, COELHO, PALETTA \& VASCONCELOS (2000) fazem uso de seis cenários alternativos, em que se varia o nível de difusão das tecnologias disponíveis. ${ }^{2}$ No cenário de adoção da tecnologia mais eficiente na transformação de biomassa em energia, o potencial da safra 2001/2002 atingiria um total de 31.147 GWh. Mesmo no caso de adoção de um cenário intermediário (Cenário 4), a geração de excedente de energia pelo setor sucroalcooleiro paulista seria suficiente para cobrir integralmente a redução de consumo imposta pelo racionamento de energia, no mesmo período, em toda a Região Sudeste, que atingiu um valor médio de 2.155 GWh por mês. Em síntese, não há restrições tecnológicas à geração de excedentes de energia pelo setor sucroalcooleiro. Cabe investigar, portanto, porque as usinas continuam a operar com tecnologias menos eficientes no aproveitamento da biomassa.

A indústria de energia elétrica apresenta particularidades que afetam

${ }^{2}$ Os cenários definidos pelos autores são os seguintes: 1) Sem alteração da pressão da caldeira (21 bar) e o tipo de turbina (contrapressão). Instalação de um novo turbogerador de contrapressão, mas de múltiplos estágios. Geradores são convertidos em múltiplos estágios. 2) Manutenção em 21 bar da pressão da caldeira. Instalação de gerador de extração controlada e condensação. Repotenciação da caldeira. 3) Troca da caldeira para 61 bar. Instalação de gerador novo de extração controlada e condensação. Desativação do turbogerador existente. 4) Troca da caldeira para 81 bar. Instalação de gerador novo de extração controlada e condensação, compatível com a caldeira. Desativação do turbogerador existente. 5) Cenário anterior, acrescido de investimentos necessários à redução do consumo específico de vapor de $530 \mathrm{~kg} / \mathrm{t}$ para $450 \mathrm{~kg} / \mathrm{t}$. 6) Cenário anterior, acrescido da utilização da palha como combustível, durante a safra, mediante investimentos pertinentes. 
as decisões da indústria sucroalcooleira em sua atividade de co-geração de energia. Por conta da impossibilidade de armazenamento, da sazonalidade de produção e consumo, do limite de transmissão dentro de um pool de energia e da grande sensibilidade dos custos marginais em relação à quantidade produzida, a energia elétrica tende a apresentar grande volatilidade de preços (POKALSKY e ROBINSON, 1997; BURCHETT \& MOFFAT, 1997). Isso faz com que o uso de uma estrutura de governança de mercado, baseado no sistema de preços, para a comercialização da energia elétrica, apresente custos associados a essa intensa volatilidade.

\section{Metodologia}

Com a finalidade de se investigar os entraves para a ampliação da oferta de excedentes de energia elétrica pelo setor sucroalcooleiro, optou-se por um estudo de multi-caso, em que pudessem ser avaliadas as condições de contexto relevantes para a opção da tecnologia de co-geração e, ao mesmo, tempo, possibilitasse a indução de proposições de caráter geral, em que se pudessem associar características das usinas às suas opções tecnológicas. A opção pelos estudos de caso, entretanto, desautorizam qualquer inferência estatística a respeito do comportamento da totalidade das usinas do Sul e Sudeste do Brasil.

A coleta de dados foi baseada em entrevistas, em profundidade, com base em questionários semi-estruturados, junto a representantes de cinco usinas do setor sucroalcooleiro. O objetivo das entrevistas foi identificar o padrão de concorrência dos potencias geradores de excedentes de energia elétrica e elencar os principais fatores capazes de inviabilizar a promoção de investimentos na geração desses excedentes.

As entrevistas abrangeram o setor sucroalcooleiro paulista, sendo considerado como universo o conjunto das 120 principais unidades produtoras. Dividiu-se o universo em dez classes com igual população, ordenadas conforme o porte da empresa, definido pela quantidade moída de cana na safra 2001/2002. A média aritmética entre a quantidade moída de cana-de-açúcar do último número da classe anterior e do primeiro da classe seguinte define cada um dos nove decis que delimitam as classes de tamanho. As cinco usinas selecionadas pertencem a diferentes classes de tamanho. Os resultados estão dispostos na Tabela 1. 
Tabela 1 - Unidades produtoras do setor sucroalcooleiro, Estado de São Paulo, por decil

\begin{tabular}{c|c}
\hline Decil & Cana-de-açúcar moída (t) \\
\hline $1^{\circ}$ Decil & 512.766 \\
\hline $2^{\circ}$ Decil & 704.904 \\
\hline $3^{\circ}$ Decil & 852.291 \\
\hline $4^{\circ}$ Decil & 982.987 \\
\hline $5^{\circ}$ Decil & 1.230 .356 \\
\hline $6^{\circ}$ Decil & 1.404 .681 \\
\hline $7^{\circ}$ Decil & 1.646 .536 \\
\hline $8^{\circ}$ Decil & 2.034 .741 \\
\hline $9^{\circ}$ Decil & 2.989 .857 \\
\hline
\end{tabular}

Fonte: Resultados de pesquisa, a partir de UDOP (2003).

\section{Estudos de caso}

A seguir são apresentadas, de modo sucinto, as principais características de cada uma das cinco usinas. Por motivo de sigilo, a pedido dos entrevistados, os nomes das usinas foram omitidos.

\section{Usina $A$}

Essa usina localiza-se na região de Ribeirão Preto, moendo na safra 2001/2002 acima de três milhões de toneladas de cana-de-açúcar, sendo, portanto, caracterizada como da classe de maior porte. A usina termelétrica, implantada em 1945, apresenta oito caldeiras, onde se queima bagaço de cana-de-açúcar, produzindo o vapor necessário ao acionamento das turbinas de preparo e moagem.

Em 1973, a empresa instalou dois geradores de $3.125 \mathrm{kVA}$ e dois de 5.000 kVA cada, ainda sem estar em paralelo com a Companhia Paulista de Força e Luz - CPFL e sem comercializar excedentes. Em 1994, a empresa promoveu investimentos em paralelismo - o que configura um investimento necessário à comercialização de energia - e passou a comercializar excedentes com a concessionária local. Numa primeira fase, durante 2,5 anos, a usina comercializou cinco MW com a CPFL. Em 1998, a empresa instalou mais um gerador de 7,5 MWA, gerando uma potência adicional de 6,5 MW. No total, passou a comercializar entre 
8 e 10 MW à concessionária local. Em março de 2003, a usina realizou nova expansão com o objetivo de comercializar um total de $30 \mathrm{MW}$.

A razão de eficiência da usina, em termos de aproveitamento do combustível, tem sido, na média, de 2 a 2,1 toneladas de bagaço para cada MWh gerado. Todavia, quando se considera somente a eficiência do sistema em condensação, a eficiência média aumenta, pois duas toneladas de bagaço passam a gerar em torno de 2,5 MWh.

Embora a empresa, historicamente, tenha comercializado bagaço com as indústrias citrícolas e usinas sucroalcooleiras locais, sua meta é estocá-lo com a finalidade de gerar entre seis e sete MW na entressafra. O aproveitamento da palha também está sendo testado pela empresa. De acordo com o entrevistado, num raio de $15 \mathrm{~km}$ da usina, a palha será recolhida, sem enfardamento e transportada à unidade termelétrica. Sem o enfardamento, o volume será elevado, mas não haverá o custo de enfardamento, de "desenfardamento", de "afofamento" e de investimento em máquinas para tais atividades. A palha, que apresenta um poder calorífico semelhante ao do bagaço, será misturada ao bagaço e queimada nas caldeiras. Há, portanto, perspectivas de ampliação do uso de biomassa.

Em relação ao custo de oportunidade na formação da cama de proteção ao solo, a empresa investiu em um equipamento norte-americano que retira a cana e a palha deixando o mínimo necessário para a proteção do solo. Dessa forma, retira apenas o excesso de palha, não havendo necessidade em investimentos em proteção ao solo. A mecanização na colheita está em torno de $50 \%$, representando uma boa capacidade para expansão no aproveitamento da palha como insumo na geração.

As estratégias da empresa têm obedecido dois objetivos principais: a) garantir a auto-suficiência futura para suas unidades industriais; e b) garantir uma receita estável com a venda de excedentes para o setor elétrico. Com referência ao primeiro objetivo, a empresa acredita que os mercados de açúcar e álcool são promissores e há necessidade de garantir o fornecimento de energia para as unidades industriais no futuro, havendo, portanto, necessidade de investimentos preventivos. Desse modo, a comercialização de excedentes decorre, sobretudo, da antecipação da necessidade futura de energia, não consistindo, portanto, uma estratégia primária de longo prazo. 
Na safra 2003/2004, a usina estava com um contrato firme de $27 \mathrm{MW}$, por dez anos, e $3 \mathrm{MW}$ em energia interruptível. Esses $3 \mathrm{MW}$ são considerados estratégicos, pois conforme se apresentem novas oportunidades de melhoria no preço da energia elétrica, os contratos fechados sob essas novas condições servem para pressionar a concessionária local a fornecer melhores condições para o contrato firme, quando de sua renegociação.

A empresa já comercializou no mercado spot via Mercado Atacadista de Energia (MAE), ${ }^{3}$ todavia, até a data da entrevista (março/2003), não havia recebido pela energia disponibilizada no MAE, representando uma quebra contratual. Considerando um preço conservador de fechamento de $\mathrm{R} \$ 60 / \mathrm{MWh}$, a empresa teria de $\mathrm{R} \$ 2$ a 3 milhões para receber à época. Posteriormente, as pendências comerciais foram liquidadas no âmbito do antigo MAE.

Em 1999, a empresa foi a primeira do setor sucroalcooleiro a comercializar com o consumidor livre, localizado na área de concessão de outra distribuidora de energia. A usina sucroalcooleira pagou os custos de conexão e transporte à CPFL e a mais duas outras concessionárias. Com a CPFL, na época, a usina tinha um contrato de $5 \mathrm{MW}$ e estava gerando $8 \mathrm{MW}$. A CPFL pagava aos $5 \mathrm{MW}$ como tarifa firme e aos três MW restantes como tarifa interruptível (entre R $\$ 2,00$ a $\mathrm{R} \$$ 3,00 por $\mathrm{MWh}$ ). Na tarifa interruptível não havia um compromisso de fornecimento continuo à CPFL. Assim, a usina pôde fechar um contrato de fornecimento com o consumidor livre, no qual a receita líquida da empresa foi de $\mathrm{R} \$ 16 / \mathrm{MWh}$ (já retiradas as comissões da comercializadora que elaborou a operação e os custos de transporte). Em seqüência ao fechamento desse contrato, a CPFL passou a oferecer a mesma receita líquida à usina, tentando forçar um rompimento do contrato com o consumidor livre, fato que evidencia que as condições de negociação afastam-se do modelo de concorrência perfeita, sendo o preço definido a partir das alternativas de venda.

A opção por uma tecnologia mais eficiente acarreta custos irrecuperáveis, de tal modo que a interrupção no fornecimento de excedentes não elimina os custos previamente incorridos. Esse fato motiva a que empresas aceitem valores inferiores ao ideal, pois o sistema foi equili-

${ }^{3}$ Com a implantação do "Novo Modelo Institucional do Setor Elétrico, o MAE foi substituído pela Câmara de Comercialização de Energia Elétrica (CCEE). 
brado para geração de excedentes e, nesses casos, os custos associados à geração de excedentes são inferiores ao das usinas entrantes, que ainda necessitam realizar os investimentos para tornarem-se produtores independentes de energia elétrica.

A empresa entrou em negociação com a Ecoenergy para promover a venda de certificados de créditos de carbono. Na opinião do entrevistado, as dificuldades residem na burocracia na medição/contabilização das toneladas evitadas de carbono, realizada por auditoria externa credenciada pelo Banco Mundial. Para o entrevistado, por bom tempo esse mercado vai ainda apresentar-se ilíquido e a empresa receia que, uma vez incorrido em todos os custos de certificação (inclusive os das comissões às consultorias e auditorias), possa encontrar dificuldades na comercialização dos créditos obtidos.

\section{Usina $B$}

A empresa localiza-se na região do rio Mogi Guaçu, moendo entre 1,5 e 3 milhões de toneladas de cana-de-açúcar na safra 2001/2002, situando-se na faixa das $30 \%$ maiores. Utiliza, sobretudo, o bagaço na geração de energia, que é queimado nas fornalhas de quatro caldeiras, sendo duas delas conectadas ao processo de termeletricidade; as outras duas, normalmente, produzem vapor para acionamento das turbinas de preparo, moagem e do processo de fabricação de açúcar, além das turbobombas.

Implantada em 1976, a usina termelétrica apresenta duas turbinas de contrapressão, conectadas a dois geradores elétricos de igual potência, de $3.750 \mathrm{kVA}$, que produzem energia nas tensões primárias de 13,8 $\mathrm{kV}$ e $2,4 \mathrm{kV}$. Alguns equipamentos da termelétrica foram adquiridos de uma firma que compõe o mesmo grupo econômico da usina sucroalcooleira, representando uma estratégia de integração vertical.

A usina produz em torno de $85 \%$ de suas necessidades energéticas adquirindo energia da concessionária local durante a entressafra. Dependendo do teor de fibra da cana e dada a opção por uma tecnologia menos eficiente na transformação da biomassa em energia, há períodos em que ocorre a falta de bagaço. Nesse período, as necessidades de energia elétrica são atendidas pela concessionária local - a Elektro. 
Ademais, também está em estudo o aproveitamento da palha, promovendo-se um orçamento para a compra de uma máquina específica para picar a palha no campo e promover seu enfardamento ainda no campo para, posteriormente, ser transportada pelos caminhões da usina.

No início da construção do parque de geração, a estratégia da empresa foi de investimento em uma unidade de geração capaz de atender a planta industrial e ainda de gerar excedentes. Na ocasião, os objetivos dessa estratégia eram semelhantes aos da Usina A: a) aproveitamento de oportunidade de lucro se o preço da energia elétrica comercializada com o setor elétrico tornar-se atraente; e b) investimento na sua autosuficiência futura.

A usina gera 1,5 MW em excedentes que é comercializado com a Tradener - agente comercializador localizado no Paraná, cujo controle acionário pertencia, à época, à concessionária estadual - a Copel. Para tanto, foi firmado um contrato de uso e de conexão da rede de transmissão da Elektro. O contrato com a Tradener foi firmado durante o racionamento, em 2001, sendo o prazo de fornecimento por cinco anos. Na época, o valor oferecido pela Elektro foi inferior ao proposto pela Tradener, mesmo incluindo os custos de conexão e de transporte, o que mostra que a ampliação das alternativas de comercialização é um fator essencial na comercialização de excedentes de energia elétrica.

Todavia, considerando a conjuntura atual, na qual o preço de compra da energia necessária para a entressafra está superior ao de venda à Tradener, a intenção da usina é de, vencendo o contrato com a empresa comercializadora, fechar um contrato de permuta com a Elektro, pois a usina detém uma outra unidade que se apresenta deficitária, adquirindo energia elétrica da Elektro até mesmo durante a safra. Assim, a estratégia de comercialização de excedentes é substituída pela estratégia de auto-suficiência do grupo empresarial, considerada prioritária.

\section{Usina $C$}

Criada em $1^{\circ}$ de março de 1985 , como sociedade por cotas de responsabilidade limitada e baixo capital inicial, em setembro do mesmo ano foi transformada em sociedade anônima. Até a safra passada, apresentava uma área cultivada de 15 mil hectares. Com uma pro- 
dução de cana moída entre 1,3 e 1,8 milhão de toneladas, a Usina C oscilou entre o $5^{\circ}$ e o 8 o decil.

O bagaço de cana é a fonte energética primária usada para a produção de vapor necessário ao acionamento das turbinas de preparo e moagem, da turbobomba e para a geração de energia elétrica. O vapor é gerado em quatro caldeiras e aciona duas turbinas de contrapressão, às quais se incorporam dois geradores elétricos com potência nominal de 3.125 e 1.750 kVA. O conjunto de geração está em operação desde a primeira safra da usina, em 1986. Para situações de emergência, existe uma unidade de combustão interna a óleo diesel de $325 \mathrm{kVA}$. A tecnologia adotada não é a de última geração no aspecto de eficiência energética: são turbinas de múltiplos estágios, mas não de extracondensação. Entretanto, a parte de proteção (relés e controladores) do sistema elétrico é considerada de última geração.

A unidade industrial está dimensionada para atendimento às necessidades de fabricação de açúcar e álcool, sendo utilizado o bagaço de cana como combustível. Na entressafra e em eventuais falhas de geração, a Companhia Paulista de Força e Luz (CPFL) atende as necessidades da usina. Do total de bagaço produzido, $60 \%$ cumprem a função de combustível na geração de vapor, $30 \%$ são comercializados para outras usinas sucroalcooleiras da região, para uma fábrica de papel e celulose e a uma processadora de óleo vegetal. As empresas demandantes de bagaço adquirem o combustível posto na usina e a finalidade é também para geração de energia (na forma de vapor e/ou energia elétrica). O restante, no total de $10 \%$, fica para formação de estoque de segurança (para o início da próxima safra ou para eventual interrupção no fornecimento da distribuidora local de energia elétrica).

Em torno de $60 \%$ a $70 \%$ da colheita da cana é mecanizada, mas não há intenção no aproveitamento de palhas e ponteiros, pois são utilizados para retenção de umidade e proteção do solo (formação de cama), não havendo nenhum estudo para tanto, o que é consistente com a estratégia de autoconsumo da biomassa. Sendo o bagaço suficiente para suas próprias necessidades durante a safra, o custo de oportunidade da palha torna-se muito baixo.

Para a empresa ofertar excedentes de energia elétrica, haveria necessidade de investimentos em construção civil (ampliação da casa de 
força), na compra de novos equipamentos geradores e em linhas de transporte para disponibilizar a energia à CPFL. Esses investimentos demandariam cerca de seis meses para entrarem em operação, fato que, mesmo durante a crise de energia, desmotivou a diretoria da empresa, pois havia incerteza quanto à manutenção do preço nos patamares do auge do racionamento em 2001 e os investimentos deveriam ser realizados na entressafra, já que a usina não poderia paralisar suas atividades no meio da safra para atendimento à demanda surgida com o racionamento em meados de 2001. Mais uma vez, os custos irrecuperáveis, somados ao período de maturação de investimento, impedem uma resposta rápida da oferta de energia co-gerada às oscilações de preço.

\section{Usina $D$}

Instalada na região de São João da Boa Vista (SP), a implantação da destilaria ocorreu em 1980, para produção de álcool carburante. Em 1995, com o arrefecimento do Programa Nacional do Álcool, foi instalada uma fábrica de açúcar, com sistema de vácuo contínuo. O cultivo de cana-de-açúcar envolve o arrendamento, até o ano 2010, de cerca de dois mil hectares. Não obstante, parcerias com outros proprietários e fornecedores elevaram a área de cultivo para 16,6 mil hectares, sendo que a firma somente detém direito de propriedade sobre 50 hectares, onde se localiza a planta industrial.

Embora a capacidade de esmagamento por safra de cana-de-açúcar seja da ordem de 1,45 milhão de toneladas, a unidade moeu na safra 2001/2002 entre 900 mil e 1,23 milhão de toneladas de cana, o que a coloca entre o $3^{\circ}$ e o $5^{\circ}$ decil (entre as $30 \%$ e $50 \%$ menores).

O sistema de geração busca atender a auto-suficiência, não gerando excedentes. Mesmo que houvesse sobra de bagaço, o gerador seria o fator limitante na expansão da geração, pois o sistema trabalha com fator de carga entre $96 \%$ e $98 \%$, havendo necessidade ainda de compra de energia elétrica da concessionária local, mesmo durante a safra. Essa restrição no atendimento às necessidades energéticas é um dos principais motivos para a desativação de uma destilaria anexa.

Mesmo havendo turbinas de múltiplos estágios, ainda há turbinas de simples estágios, significando que existem oportunidades de inves- 
timento que proporcionariam a formação de estoques de bagaço, com a elevação da eficiência energética do sistema de geração. A empresa detém uma vantagem estratégica que é a de o grupo econômico possuir uma outra unidade próxima (em torno de $70 \mathrm{~km}$ ), de tal forma que há trocas de bagaço entre as unidades, conforme suas necessidades industriais. Ainda assim, antes do investimento em eficiência energética - para maximização no uso do bagaço - a usina desenvolve um projeto para utilização da palha como forma de ampliar a quantidade de biomassa utilizada.

\section{Usina $E$}

Localizada na região de Ribeirão Preto, a usina é resultado da diversificação das atividades da empresa controladora, que é do segmento da construção civil. Na safra 2001/2002, a usina moeu entre 800 mil e 1,2 milhão de toneladas de cana, oscilando entre o $2^{\circ}$ e o $5^{\circ}$ decil. A fonte energética primária é o bagaço de cana, que é queimado nas fornalhas de três caldeiras, suprindo as quantidades de vapor necessárias ao acionamento das turbinas de preparo, o difusor, a turbina do terno de secagem, as turbobombas e para a geração de energia elétrica.

Utiliza-se para geração de energia o ciclo térmico de Rankine, aproveitando o vapor das caldeiras para acionar duas turbinas de contrapressão, às quais se acoplam, por meio de redutores de velocidade e dois geradores elétricos: um de 7.500 kVA (instalado em 1996) e outro de $3.750 \mathrm{kVA}$ (instalado em 1986). São turbinas a vapor de contrapressão, de 21 quilos e de múltiplos estágios. O conjunto de geração está em operação desde 1986, sendo a energia gerada na tensão primária de $13,8 \mathrm{kV}$, atendendo praticamente a demanda da usina nos meses de safra. Na entressafra, a usina é atendida pela CPFL.

A eficiência produtiva é inferior à obtida com tecnologias de ponta, sendo gerado 530 quilos de vapor com uma tonelada de bagaço. As turbinas das moendas, por exemplo, são de único estágio e poderiam ocorrer investimentos em turbinas de múltiplos estágios, assim como ocorre com a geração de energia elétrica, fato que possibilitaria a produção de maior quantidade de vapor e, por conseqüência, economia de bagaço.

Apesar de a empresa vender excedentes para a CPFL, a estratégia 
principal é semelhante à da Usina $\mathrm{C}$, mas com a preocupação de manter uma capacidade estratégica ociosa para o futuro. Para atender essa estratégia, conforme mencionado, há necessidade de gerar energia elétrica para promover a redução do vapor, na pressão específica à unidade industrial. Porém, as necessidades de energia elétrica para a unidade industrial são inferiores à geração total de eletricidade. Assim, há excedentes que são comercializados à distribuidora local.

A venda de excedentes ocorre desde 2001, quando do advento da crise de energia, sendo a CPFL a única compradora. Até dezembro de 2002, o contrato da CPFL previa a venda de $900 \mathrm{MWh}$, a R \$ 70,00/MWh (reajustado anualmente pelo IGPM). A CPFL ofereceu o contrato pelo prazo de dez anos, mas a diretoria da usina considerou o prazo de cinco anos mais adequado, pois acreditava que o cenário da crise de energia poderia apresentar continuidade.

Na safra 2002/2003, a usina estava gerando entre 1.100 MWh e 1.200 MWh, bem superior aos $900 \mathrm{MWh}$ contratados. Até janeiro de 2003, o excedente ao contratado era comercializado ao mesmo preço de $\mathrm{R} \$ 70,00 / \mathrm{MWh}$. Todavia, a partir daquela data, a CPFL unilateralmente propunha aditar o contrato no sentido de pagar o excedente aos 900 MWh o valor vigente no mercado spot, na época R $\$ 5,00 / \mathrm{MWh}$, um preço 14 vezes inferior ao inicialmente contratado.

Existe sobra de bagaço, que é comercializada essencialmente com a fábrica de papel e celulose Rio Pardo, localizada em Santa Rita do Passa Quatro. Há, ainda, a formação de estoque de bagaço, que é poupado para promover a partida nas caldeiras no início de cada safra. A colheita mecanizada representa cerca de $25 \%$ do total e não ocorre o aproveitamento das palhas e ponteiros por dois motivos principais: a) por sua função na preservação do solo e b) pelos investimentos que seriam necessários para o seu aproveitamento (enfardadora, caminhões para transporte dos fardos, mão-de-obra para separar o fardo etc.).

Em relação ao mercado de créditos de carbono, os custos envolvidos na certificação são considerados fortes barreiras à entrada nesse mercado. Todavia, o fato agravante tem sido o estágio atual desse mercado, onde a falta de liquidez na comercialização dos créditos é freqüente. Dessa forma, considerando que as empresas certificadoras têm adotado a estratégia de cobrança de seus serviços antes da venda efetiva dos 
créditos, a diretoria da usina, apesar de estudar o assunto, tem adotado a estratégia de aguardar até o momento em que esse mercado apresente mais liquidez para não incorrer em sunk costs.

\section{Discussão e análise comparada}

Uma primeira resposta para a presença de tecnologias de menor eficiência energética poderia vir da existência de custos irrecuperáveis (sunk costs) associados às tecnologias anteriores, que tornariam elevados os custos de mudança para uma nova tecnologia. Entretanto, mais de $65 \%$ das unidades de co-geração existentes completaram vinte anos de atividade em 2004, o que implica que a tecnologia em uso não representa, em 2004, um custo irrecuperável relevante, que poderia obstruir o processo de mudança técnica e, portanto, inibir a geração de excedentes de energia elétrica por parte do setor sucroalcooleiro. A escolha da tecnologia parece subordinar-se a uma estratégia comum a todas as usinas pesquisadas: a prioridade para a auto-suficiência em energia, a qual pode ser obtida por meio de tecnologias de menor eficiência energética, com custos de investimento ( $\mathrm{R} \$ \mathrm{MW}$ instalado) inferiores.

A fim de investigar os principais determinantes das estratégias de geração de excedentes de energia, esta seção utiliza os resultados dos estudos de caso, sintetizados na Tabela 2. 
Tabela 2 - Resumo dos principais resultados das entrevistas, Usinas A a E

\begin{tabular}{|c|c|c|c|c|c|}
\hline & Usina A & Usina B & Usina C & Usina D & Usina $\mathrm{E}$ \\
\hline Porte & Depois $9^{\circ}$ decil & $\begin{array}{c}\text { Entre } 7^{\circ} \text { e } 9^{\circ} \\
\text { decis }\end{array}$ & $\begin{array}{c}\text { Entre } 5^{\circ} \text { e } \\
7^{\circ} \text { decis }\end{array}$ & $\begin{array}{c}\text { Entre } 3^{\circ} \text { e } \\
5^{\circ} \text { decis }\end{array}$ & $\begin{array}{l}\text { Entre } 2^{\circ} \text { e } 5^{\circ} \\
\text { decis }\end{array}$ \\
\hline $\begin{array}{l}\text { Comercializa- } \\
\text { ção do baga- } \\
\text { ço in natura }\end{array}$ & Sim & Não & Sim & Não & Sim \\
\hline $\begin{array}{c}\text { Principal uso } \\
\text { do bagaço }\end{array}$ & Geração de EE & Geração de EE & $\begin{array}{c}\text { Geração de } \\
\text { EE }\end{array}$ & $\begin{array}{c}\text { Geração de } \\
\text { EE }\end{array}$ & Geração de EE \\
\hline $\begin{array}{l}\text { Estratégia } \\
\text { principal }\end{array}$ & $\begin{array}{c}\text { Geração para } \\
\text { auto-suficiên- } \\
\text { cia presente e } \\
\text { futura } \\
\end{array}$ & $\begin{array}{c}\text { Geração para } \\
\text { auto-suficiên- } \\
\text { cia presente e } \\
\text { futura }\end{array}$ & \begin{tabular}{|c|} 
Geração \\
para auto- \\
suficiência \\
presente \\
\end{tabular} & \begin{tabular}{|c|} 
Geração \\
para auto- \\
suficiência \\
presente \\
\end{tabular} & $\begin{array}{l}\text { Geração para } \\
\text { auto-suficiên- } \\
\text { cia presente e } \\
\text { futura }\end{array}$ \\
\hline $\begin{array}{c}\text { Venda de } \\
\text { excedentes } \\
\text { de EE }\end{array}$ & Sim & Sim & Não & Não & Sim \\
\hline $\begin{array}{c}\text { Capacidade } \\
\text { ociosa } \\
\text { estratégica de } \\
\text { geração } \\
\end{array}$ & $\begin{array}{c}\text { Sim } \\
\text { - investimento } \\
\text { em "máquinas } \\
\text { grandes" } \\
\end{array}$ & $\begin{array}{c}\text { Sim } \\
\text { - investimento } \\
\text { em "máquinas } \\
\text { grandes" }\end{array}$ & Não & Não & $\begin{array}{c}\text { Sim } \\
\text { - investimento } \\
\text { em "máquinas } \\
\text { grandes" }\end{array}$ \\
\hline $\begin{array}{c}\text { Estratégia } \\
\text { para geração } \\
\text { firme (base } \\
\text { anual) } \\
\end{array}$ & $\begin{array}{l}\text { Sim - planeja } \\
\text { estocar bagaço } \\
\text { para geração } \\
\text { de EE anual } \\
\end{array}$ & Não & Não & Não & Não \\
\hline Uso da palha & Em teste & Em teste & $\begin{array}{c}\text { Sem } \\
\text { previsão }\end{array}$ & Em estudo & Sem previsão \\
\hline $\begin{array}{l}\text { Estratégias } \\
\text { específicas }\end{array}$ & $\begin{array}{c}\text { Geração de } \\
\text { excedentes é } \\
\text { estratégica à } \\
\text { imagem social } \\
\text { do grupo }\end{array}$ & $\begin{array}{c}\text { Promove } \\
\text { integração } \\
\text { vertical para } \\
\text { trás }\end{array}$ & $\begin{array}{c}30 \% \text { do } \\
\text { total de } \\
\text { bagaço } \\
\text { comercia- } \\
\text { lizados in } \\
\text { natura }\end{array}$ & $\begin{array}{c}\text { Grupo } \\
\text { possui } \\
\text { outra } \\
\text { unidade } \\
\text { próxima } \\
\text { que } \\
\text { fornece } \\
\text { bagaço }\end{array}$ & $\begin{array}{l}\text { Geração de } \\
\text { excedentes é } \\
\text { estratégica à } \\
\text { estabilização da } \\
\text { receita global }\end{array}$ \\
\hline $\begin{array}{c}\text { Créditos de } \\
\text { carbono }\end{array}$ & Em negociação & Sem previsão & $\begin{array}{c}\text { Sem } \\
\text { previsão }\end{array}$ & $\begin{array}{c}\text { Sem } \\
\text { previsão }\end{array}$ & Em estudo \\
\hline
\end{tabular}

Fonte: Resultados de Pesquisa (2003).

Em síntese, a Tabela 2 revela que a principal estratégia comum às usinas pesquisadas é a geração de energia para sua auto-suficiência. Aquelas que exploram mais intensamente a comercialização de excedentes de energia planejam a expansão futura da atividade sucroalcooleira, 
a qual demandará mais energia no futuro. Portanto, a comercialização de excedente nessas usinas pode ser interpretada como parte de uma estratégia de auto-suficiência futura. Deve-se salientar também que, com o sobre-investimento, ocorre o aproveitamento de economias de escala, representado pela queda do custo do investimento por MWh instalado.

Mesmo assim, nota-se que o sobre-investimento - fator indutor à comercialização de excedentes - está presente tanto para pequenas quanto grandes usinas, pois a necessidade de garantir o fornecimento futuro de energia independe do porte da unidade industrial. Dessa forma, pode-se inferir que a opção pela comercialização de excedentes não está relacionada fortemente com o porte da unidade industrial, conforme se pôde observar analisando o perfil das Usinas C e E. Essa conclusão é relevante para o delineamento de políticas públicas, identificando, a princípio, não ser fundamental a estratificação da política setorial governamental por porte de firma.

Os estudos de caso sugerem que há entraves à estratégia de venda de excedentes, entre os quais destacam-se: a) a volatilidade no preço da energia elétrica; b) preço do MWh gerado pelo setor sucroalcooleiro ainda não incorpora externalidades positivas, fator diferenciador do produto; c) profusão de instituições e regulamentações que geram incertezas quanto ao cumprimento estrito do contrato de venda de energia elétrica; d) existência de usos alternativos para o bagaço e a palha e e) falta de liquidez no mercado de créditos de carbono. Em outras palavras, há custos diversos associados à venda de energia excedente.

Por outro lado, a produção para sua auto-suficiência possibilita vantagens pecuniárias derivadas do custo evitado com a aquisição da energia do setor elétrico, considerando que o preço de venda é consideravelmente mais baixo que o de compra (preço da energia, preço do transporte e custos de transação na comercialização). Os estudos de caso revelam que o principal custo na comercialização não está na tarifa de uso das redes, uma vez que há contratos com consumidores livres localizados em regiões fora da área da concessionária, os quais são vantajosos mesmo considerando as tarifas de transporte (até porque há subsídios quanto aos custos de transporte na comercialização por fontes alternativas). A diferença de preços de compra e venda deve originar-se, sobretudo, dos custos de transação na comercialização. 
A opção de aquisição das necessidades de energia elétrica via mercado poderia prejudicar a competitividade das atividades principais do setor. Considerando que o custo de produção médio estimado da energia elétrica gerada para o consumo próprio apresenta um valor de $\mathrm{R}$ \$22,34 por MWh, ${ }^{4}$ há vantagens pecuniárias na integração vertical, pois na aquisição de energia (MWh) da CPFL, ao preço de R $\$ 142,85$ por MWh, o custo seria $439,4 \%$ superior ao obtido com a opção de integração vertical. Sendo o setor sucroalcooleiro considerado energo-intensivo, a competitividade dessa indústria estaria fortemente comprometida na ausência de integração vertical (auto-suficiência).

Além disso, as economias na produção seqüencial de eletricidade e vapor (co-geração) tornam o custo total da firma na produção dos dois produtos consideravelmente menor do que o custo de duas ou mais firmas produzirem separadamente esses mesmos produtos, a preços dados de insumos. Assim, a presença de economias derivadas do processo de co-geração, promovendo reduções nos custos médios, também favorece a integração vertical nessa indústria.

Em síntese, há custos muito elevados associados à comercialização via mercado, seja para a compra de energia, seja para a venda de excedentes, o que explica a predominância da estratégia de auto-suficiência. Esta é, em essência, a causa de persistência de tecnologias de menor eficiência energética e, conseqüentemente, da pouca relevância dos excedentes de energia elétrica do setor sucroalcooleiro. Dado que as tecnologias em operação permitem a auto-suficiência, não há estímulos para que as usinas busquem tecnologias de maior eficiência energética, que resultariam em excedentes comercializáveis.

Apesar de o principal emprego do bagaço ser a geração de energia elétrica, a estratégia de pesquisa em técnicas de aproveitamento da palha pode significar a intenção futura de emprego alternativo do bagaço, sobretudo àqueles que não apostam no desenvolvimento da atividade de comercialização de excedentes sucroalcooleiros. O uso alternativo do bagaço poderia ser a sua comercialização para outros agentes, seu estoque para garantir a geração de energia elétrica em caráter "firme” (du-

${ }^{4}$ Informação do MME (2003), constante do "Documento de Consulta Pública MME - julho de 2003 - Valor Econômico da Tecnologia Específica da Fonte”. 
rante o ano todo) ou ainda o estabelecimento de contratos de permuta com a concessionária, equacionando problema de sazonalidade.

\section{Considerações finais e implicações de política pública}

Sendo uma indústria energo-intensiva, o elevado custo associado à comercialização da energia elétrica - seja na venda de excedentes, seja na aquisição para consumo próprio - constituem a explicação mais plausível para a auto-suficiência na produção de energia elétrica pelo setor sucroalcooleiro, aliada à pequena geração de excedentes de energia para comercialização. Das cinco usinas estudadas, as três que comercializam excedentes de energia o fazem como parte de uma estratégia de antecipação da necessidade futura de auto-suficiência. Havendo custos associados à venda de excedentes de energia, não há incentivos à utilização de tecnologias de maior eficiência.

Os estudos de caso sugerem que o porte das firmas não é uma variável relevante nas estratégias de venda de excedentes de energia, não sendo, portanto, aconselhável utilizar esse critério na elaboração de políticas públicas. Estas devem voltar-se, sobretudo, para a redução dos custos associados à comercialização de excedentes de energia, como mecanismos para atenuar a volatilidade de preços e aumentar as garantias aos contratos de suprimento de médio e longo prazos, semelhantes às adotadas no Programa de Incentivo às Fontes Alternativas (PROINFA). De acordo com a ELETROBRÁS (2004), o PROINFA, instituído pela Lei $n^{0} 10.438$, de $26 / 04 / 2002$ e revisado pela Lei $n^{0} 10.762$, de $11 / 11 / 2003$, tem como objetivo a diversificação da matriz energética brasileira e a busca por soluções de cunho regional com a utilização de fontes renováveis de energia. O Programa promoverá a implantação de 3.300 MW de capacidade, divididos igualmente entre as fontes (biomassa, pequenas centrais hidrelétricas e eólicas), em instalações de produção com início de funcionamento previsto para até 30/12/2006, sendo assegurada, pela ELETROBRÁs, a compra da energia a ser produzida, no período de 20 anos, dos empreendedores que preencherem todos os requisitos de habilitação e projetos selecionados em chamada pública.

O PROINFA atraiu 426 projetos para a geração de 6.601 MW de energia, o dobro do previsto para a $1^{\text {a }}$ fase do programa, conduzindo a 
critérios de seleção que levarão em conta a cota por estado, por tipo de produtor e pela antiguidade da licença. Os projetos para energia eólica somaram 3.681,58 MW; os de pequenas centrais hidrelétricas, 1.921,17 mil MW; e os de biomassa (bagaço de cana, casca de arroz, restos de madeira e biogás) apenas 995,25 MW. ${ }^{5}$

A baixa procura pelo PROINFA pelo setor sucroalcooleiro pode ter explicação inicial no preço do MWh oferecido pela ELETROBRÁS, na operacionalização do financiamento e na estratégia dos agentes de condicionar a geração de excedentes à necessidade de auto-suficiência presente e futura. ${ }^{6}$

Independentemente do PROINFA, a pesquisa identificou que particularmente interessante é aumentar o volume de consumidores livres e amparar a comercialização entre estes e os co-geradores de energia. Da experiência dos casos, pode-se notar que a maior disponibilidade de consumidores livres/comercializadoras tem um papel de aumentar o valor esperado do MWh, assim como reduzir a volatilidade e os riscos de apropriação da renda da atividade pela concessionária local de energia. Finalmente, devido às restrições do método de pesquisa, é ainda desejável submeter essas conclusões a uma análise quantitativa, que permita generalizações para o conjunto das usinas do Sul e Sudeste. Em que pese essa limitação, a análise comparada aqui empreendida constitui um passo importante no entendimento do problema, fornecendo os subsídios preliminares para a análise qualitativa das políticas públicas voltadas à expansão da oferta de energia pelo setor sucroalcooleiro.

\section{Referências bibliográficas}

BURCHETT, S.; MOFFAT, B. Industrial and Commercial End-Users: the Transition from Ratepayer to Customer. In: The US Power Market: Restructuring and Risk Management. London: Risk Publications, 1997. cap. 18, p. 272-275.

\footnotetext{
${ }^{5}$ A energia gerada pelas usinas do programa será correspondente ao consumo do Estado de Santa Catarina (1,6 mil MW médios), e vai elevar a participação de fontes alternativas renováveis na matriz energética brasileira de $3,1 \%$ para $5,9 \%$.

${ }^{6}$ Ademais, a priori, eventuais benefícios financeiros provenientes do Mecanismo de Desenvolvimento Limpo - MDL serão apropriados à conta PROINFA-ELETROBRÁS e não ao investidor.
} 
COELHO, S. T. Mecanismo para implementação da co-geração de eletricidade a partir de biomassa: um modelo para o Estado de São Paulo. São Paulo, 1999. Tese (Doutorado) - Programa Interunidades de PósGraduação em Energia, Universidade de São Paulo.

COElHO, S. T.; PALETTA, C. E. M.; VASCONCElOS, M. A. Medidas mitigadoras para a redução de emissões de gases de efeito estufa na geração termelétrica. Brasília: Dupligráfica, 2000, 222p.

CORREAA NETO, V. Análise de viabilidade da co-geração de energia elétrica em ciclo combinado com gaseificação de biomassa de canade-açúcar e gás natural. Rio de Janeiro, 2001. Dissertação (Mestrado) - Programa de Pós-Graduação em Planejamento Energético, Universidade Federal do Rio de Janeiro.

ELETROBRÁS/UFRJ. Séries econômico-financeiras de empresas de energia elétrica - demonstrações de 31/12/98. Rio de Janeiro, RJ, jul. 1999.

POKALSKY, J.; ROBINSON, J. Integrating Physical and Financial OTC Contract Portfolios. In: The US Power Market: Restructuring and Risk Management. London: Risk Publications, 1997. cap. 8, p. 1112-115.

SOUZA, Z. J. geração de energia elétrica excedente no setor sucroalcooleiro: entraves estruturais e custos de transação. Uma Avaliação das formas de comercialização da energia co-gerada pelo setor sucroalcooleiro. São Carlos, 2003. Tese de Doutorado - Departamento de Engenharia de Produção, Universidade Federal de São Carlos.

SYS, P. A. Cenários tecnológicos. In: Ampliação da oferta de energia através da biomassa. São Paulo: FIESP/CIESP, 2001.

TOlMASQUim, M. T, SZKLO, A. S, SOARES, J. B. Potential Use For Alternative Energy Sources In Brazil. In: ANNUAL PETROBRAS CONFERENCE, Oxford, Inglaterra, 2002.

Recebido em setembro de 2004 e revisto em abril de 2006 